\title{
Exploring Instances of Feminism Movement in a Reggaeton Song: A Multi-Semiotic Critical Discourse Analysis
}

\author{
María José Mosqueda Ramírez \\ University of Guanajuato, MEXICO \\ Division of Social Sciences and Humanities
}

Received: 12 June 2021 - Accepted: 7 August 2021 - Published Online: 20 August 2021

\begin{abstract}
This study analyses the instances of feminism in a reggaeton song consulting a Multimodal Critical Discourse Analysis (MCDA). It interprets these instances and provides a description to what they intend to present from a feminist perspective. It also attempts to find out what are the visual semiotic choices that the song presents to the audience such as the attributes, settings and salience. Finally, it aimed to explore how these elements are represented in the video. To achieve the goal of the study, I created a table where I included the visual semiotic elements previously mentioned. This table presents the three scenes that were chosen to be analyzed from the video and the semiotics elements according to the MCDA by Machin and Mayr (2012). Regarding the results of the study, they show that the visuals of the video represent instances where women have the power to stop men from abusing them. Even when the visuals show some fictional scenes, the interpretation is that women have the right and the power to make themselves be respected by men. In addition, the results showed as a reminder that there are movements which are there to help women in these injustices. Finally, in the last part of the song the final idea about the resistance of men violating women is represented as the final result of this study.
\end{abstract}

Keywords: Critical discourse analysis, semiotic analysis, feminism, machismo, reggaeton.

\section{Introduction}

The aim of this paper is to present a visual analysis of the song Yo perreo sola from the reggaeton singer Bad Bunny. Music is without a doubt one of the most important forms of expression in different cultures. Back in the day when the Reggaeton genre became popular, one of the strongest criticism against was that in most of their songs women appeared as an object of sex denigrating them in the emotional and physical appearance. Thus, some singers have opted for representing and defending the position of not only women, but also the LGBTQ+ community. In society, there are also movements and social programs which defend and protect the rights of these groups of people. Due to the numerous social injustices, more and more individuals are taking part in these activist actions to prevent such discriminations. This video has been classified as one which supports women in their empowerment in society. Based on this, I will start this paper by proving a conceptual framework and background on the content of the video. Subsequently, I will describe the methodology that was used to conduct the analysis which refers to multimodal multi-semiotic critical discourse analysis. Next, I will present the analysis together

(C) Authors. Terms and conditions of Creative Commons Attribution 4.0 International (CC BY 4.0) apply. Correspondence: María José Mosqueda Ramírez (MA student), University of Guanajuato, Division of Social Sciences and Humanities, Guanajuato, MEXICO. E-mail: mariamosqueda23@gmail.com. 
with the discussion. Finally, the conclusion and reflection to the content of the paper will be given.

\section{Theoretical framework}

The section approaches the relevant concepts and theory by the multidisciplinary areas of research. There is also a section which explains the phenomenon being analyzed. The structure of these sections presents a background to contextualize the main themes that are touched within the analysis. Subsequently, the concepts that emerged from the analysis are described to a better understanding of the topic and the discussion. Finally, the methodological procedures and techniques are presented.

\subsection{Background}

The roles that men and women have to adopt in society has been rejected by some people and disliked by others; "our world is deeply unequal and systematic inequalities which disadvantage women and advantage men are visible around the globe" (Flood, 2015: 1). This is due to the numerous problems that these roles imply. Nowadays, the terms feminism and machismo have a strong representation and cause a great impact in society. Machismo has an extremely negative meaning due to its consequences in women's psychological and physical appearance. Paredes (1971) explains that this term could have had its origins in the Conquest, when Hernan Cortez and his conquistadors arrived in Mexico and raped the women of the Aztecs. The author also explains that the cult of male has been in history for more than four centuries. Machismo, as Basham (1976) defines it as "sexual prowess, zest of action; including verbal 'action,' caring, and above all, absolute self-confidence” (p. 127). Complementing this idea, Basham (1976) explains that from a macho's viewpoint the place of a woman is at home. This interprets that women's role is somehow limited to being a mother, wife and a sexual servant. In addition, her role includes house chores and any other activity which serves the family.

There are feminists who defend and claim for respect for women's rights because they believe that these aspects do not define women, but rather denigrates them and puts them in an unequal spot from men. There have been several programs and movements which support women and their right to stop and/or defend them for the many injustices many of them have faced in their different spheres of life. There are also activists that work to defend women and ask for the equality of both genders in the different life environments they are involved in. Flood (2015) affirms that Women's movements and feminism have mounted a sustained challenge to local and global gender inequalities, with important successes in undermining the pervasiveness and acceptability of women's subordination" (p. 1). Therefore, there is opportunity for women to have an equal position in this world as any other gender.

\subsection{Theoretical concepts: feminism and machismo.}

As society, it has been hard to identify or to set roles for women and men, especially because it is thought that they have different positions and functions. Considering the role of women, Butler (2013) assures that "the category of women is internally fragmented by class, color, age, and ethic lines, to name a few; in this sense, honoring the diversity of the category and insisting upon its definitional reification of women's experience for the diversity that exists" (p. 327). 


\section{Connell (2005) explains that,}

Equality between women and men has been a doctrine well recognized in international law since the adoption of the 1948 Universal Declaration of Human Rights (United Nations 1958), and as a principle it enjoys popular sup- port in many countries. The idea of gender equal rights has provided the formal basis for the international discussion of the position of women since the 1975-85 UN Decade for Women, which has been a key element in the story of global feminism (Bulbeck 1988). The idea that men might have a specific role in relation to this principle has emerged only recently. (p. 1801)

Even when there might be laws and other formal actions which defend women over men, there are unfair actions against women. In some parts of the world females live deeply in oppression and there is nothing they can do because if they act to ask for rights they will be murdered or sacrificed for their corrupt behavior. Even in countries where laws protect them from these violence acts, there are people who do not respect the law and take part from themselves violating the rights women have.

Feminist activist and social movements continue asking for more rights for women, but especially for people to respect that one already established by law. Connell (2005) explains that,

Gender inequalities are embedded in a multidimensional structure of relationships between women and men, which, as the modern sociology of gender shows, operates at every level of human experience, from economic arrangements, culture, and the state to interpersonal relation- ships and individual emotions. (p. 1801)

The description of women's oppression, their historical situation or cultural perspective has seemed, to some, to require that women themselves will not only recognize the rightness of feminist claims made in whether their relational attitudes, in their embodied resistance to abstract bodies, their capacity for material identification or material thinking, the nonlinear directionality of their pleasures or the elliptical and plurivocal possibilities of their writing. (p. 324)

There are several reasons that concern the inequalities between men and women as the quote above presents. Sometimes women are attacked more in one sphere or their lives; however, the claim is that this should be solved in order for women to feel secure and free in the world where they live. The author also presents four ideas that categorize men as the cause for the misfortune of women (Connell, 2005: 1801-1802):

(1) Men and boys are thus in significant ways gatekeepers for gender equality.

(2) In every statement about women's disadvantages, there is an implied comparison with men as the advantaged group.

(3) In the discussions of violence against women, men are implied, and sometimes named, as the perpetrators.

(4) In discussions of women's exclusion from power and decision making, men are implicitly present as the power holders.

The author explains in her research that men have created this image due to the attitude, behaviors and acts which they have done to women. Referring back to the second point mentioned, men have been seen as one with greater force than women to perform numerous activities. In addition, the third point exhibits a reality which have murder many women around the world. The feeling of superiority has led men to use violence with women if they feel threatened by women's actions. As a result of this, point number four reveals that men have accomplished vandalism by suppressing women to the acts of violence they perform to them. Adding to this idea, Connell (2005), affirms that the position of men has not greatly changed because, 
- Men remain a very large majority of corporate executives, top professionals, and holders of public office;

- Men hold nine out of ten cabinet-level posts in national governments, nearly as many of the parliamentary seats, and most top positions in inter- national agencies;

- Men, collectively, receive approximately twice the income that women receive and also receive the benefits of a great deal of unpaid household labor, not to mention emotional support, from women. (p. 1804)

These points show how the work area is one of the main where the inequality among women is shown. This is usually the case because women are perceived as the weak gender or the ones that are the most emotional. Thus, this has caused people to think that they are not able to cope with the complex roles in society or situations in the different spheres of life. However, just as men, they deserve and need the same opportunities in order to prove that they are capable of performing the same multifaceted activities as men do. As Blackstone (2003) states, gender roles are simple expectations that society has on individuals based on their sex. Thus, this does not determine facts about people and their sexes.

Over all, Connell (2005) explains that "moving toward a gender-equal society involves profound institutional change as well as change in everyday life and personal conduct" (p. 1801). From this, it is explained that the task involves the society in general. Flood (2015) affirms that the way in which men are part of the problem, they are also part of the solution. This is because "gender injustices will only cease when men join with women to put an end to it" (p. 3). The author adds that not only men's attitudes, but also their behaviors would have to change for gender equality to be achieved. Considering the consequences if these changes are not adapted, Chant and Guttman (2006) affirm that women could continue to suffer patriarchal power relations such as total responsibility for sexual health, family nutrition to mention few. On the other hand, Kaufman (2003) suggest to reflect on this participation from men since it can reinforce their existing power. As another consequence, Connell (2003) mentions that justice for women can be weakened.

\subsection{Critical discourse analysis as a research methodology}

As stated above, this paper aims to analyze the instances of feminism that the reggaeton song Yo perreo sola contains. This analysis is focused on a critical discourse analysis which according to Fairclough (2013) CDA has three main characteristics: (1) It is part of some form of systematic transdisciplinary analysis of relations between discourse and other elements of the social process. (2) It includes systematic analysis of texts and, (3) It addresses social wrongs. In order to do this, I have chosen three different scenes from the video which alludes to feminism instances.

The focus of this paper falls more precisely in to the explanation the author provides about one of the primary focus of CDA which is the effect of power relations and inequalities in producing social wrongs, and in particular on discursive aspects of power relations and inequalities: on dialectical relations between discourse and power, and their effects on other relations within the social process and their elements.

This focus leads to the consultation of ideologies which Fairclough (2013) defines as "a relation between meaning (and therefore texts) and social relations of power and domination" (p. 79). The author also explains that discourse analysis has four contributions to ideological analysis, these are:

a. Identifying discourses, and their linguistics realizations,

b. Tracing the texturing od relations between discourses,

c. Tracing the 'internal' (to semiosis) dialectic between discourses, genres and styles, 
d. Tracing the recontextualization of discourses (genres, styles) across structural and scalar boundaries.

Furthermore, the term hegemony also takes a role in this analysis by explaining that "it is a focus of constant struggle around points of greatest instability between classes and blocs, to construct or sustain or fracture alliances and relations of domination/subordination, which takes economic, political and ideological forms" (Fairclough, 2013: 61).

\section{Research technique}

Research question: What are the instances of feminism that the reggaeton song $Y o$ perreo sola presents?

For this analysis I consulted Multimodal Critical Discourse Analysis (MCDA). According to Machin and Mayr (2012) "is interested in showing how images, photographs, diagrams and graphics also work to create meaning, in each case describing the choices made by the author" (p. 9). This interest is presented because as the authors explain, texts will use linguistics and visual strategies to present an idea; however, these representations might not be neutral and normal. In other words, MCDA seeks to present the other modes of communication that they hide. Therefore, its job is to identify the message hidden through a description of the visuals the phenomenon presents.

More precisely, I will focus on a social semiotic theory, view and approach which is explained as one which:

- Describing and documenting the underlying resources available to those who want to communicate meaning visually and analyzing the way that they are used in settings to do particular things.

- Is concerned with the underlying available repertoire of sings and their use in context to communicate wider ideas, moods and attitudes and identities, and interested in why specific means were used to create these.

- Choices of visual elements and features do not just represent the world, but constitute it. Like language, visual communication plays its part in shaping and maintaining a society's ideologies, and can also serve to create, maintain and legitimize certain kinds of social practices.

- Is interested in the details of things like color and shape and their interrelationship in any visual design or image (Machin \& Mayr, 2012: 18-19).

The authors also explain that "visual communication, by its nature, tends to be more open to interpretation, which gives the author some degree of maneuver not permitted to language use" (p. 31). Therefore, an iconographical and iconological analysis is also appropriate for this paper. This will allow us to explore and signify discourses by individual elements in images, objects and settings. More specifically, the three visual semiotic choices that this study aims to describe from the video focus on: attributes, settings and salience. Attributes correspond to the ideas and values communicated by objects, settings are used to communicate ideas, connote discourses and their values, identities and actions and salience presents the features which have the purpose to stand out and draw attention to certain meanings.

\section{Results of the analysis}

In this part of the paper, I present the results of the analysis based on the images that were chosen to be analyzed from the video. It is important to remember that the purpose of this song and especially the visual content of the video is to raise awareness about the sexual aggression 
and the social injustices that are performed to women. From the lyrics to the visual that the song presents, these ideas about defending and respecting women are represented and symbolized. In the next analysis, the representation is deeply explained.

For this part of the analysis, there are several aspects to consider from this video. The analysis starts by considering the visual semiotic choices which Machin and Mayr (2012) explain is communication that is expressed through non-linguistic features or elements. In other words, the author states that images connote and denote ideas and messages. Then, it is through images that the singer tries to present a message to project to society. For this analysis, the visual semiotic choices that would be used for analysis are: attributes, settings and salience. For a better organization of the analysis, I have called the images to be analyzed scene 1 (Figure 1 and 2), 2 (Figure 3 and 4), and 3 (Figure 5).

In scene 1 (Figure 1 and 2), the male singer who is also the person interpreting a woman at a club wearing a bright reddish outfit, is at a higher altitude the men approaching her. In the same place, she is dancing the reggaeton song, moving around doing sensual poses. This communicates the idea that women are in total control of their decisions at the time of allowing or not a man to approach her. In this same scene, the next part is where men approach her in that high base where she is standing and since they do not stop and get close to her, she uses a magic force to stop them launching them far away from her. This scene presents how women should be in charge of who does and does not approach them. If they do not want someone to get close to them, they should have all the right to set them apart and men have to respect the decision. In other words, women have the same power to make decisions and take the same positionally than men in this world.

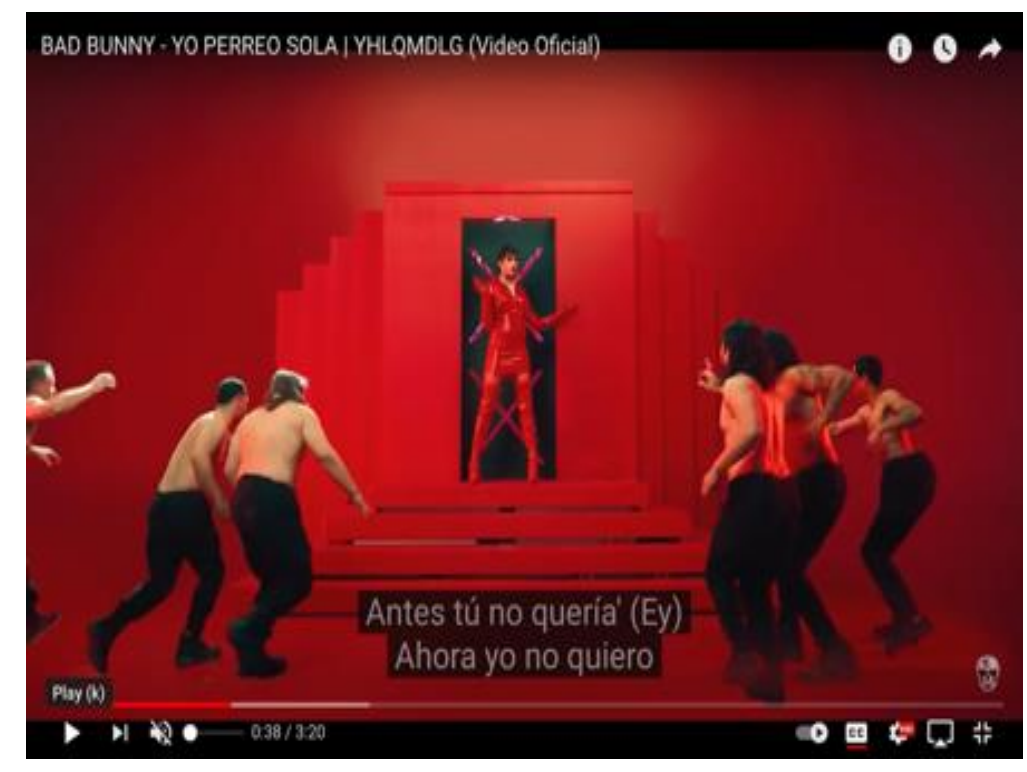

Figure 1. 


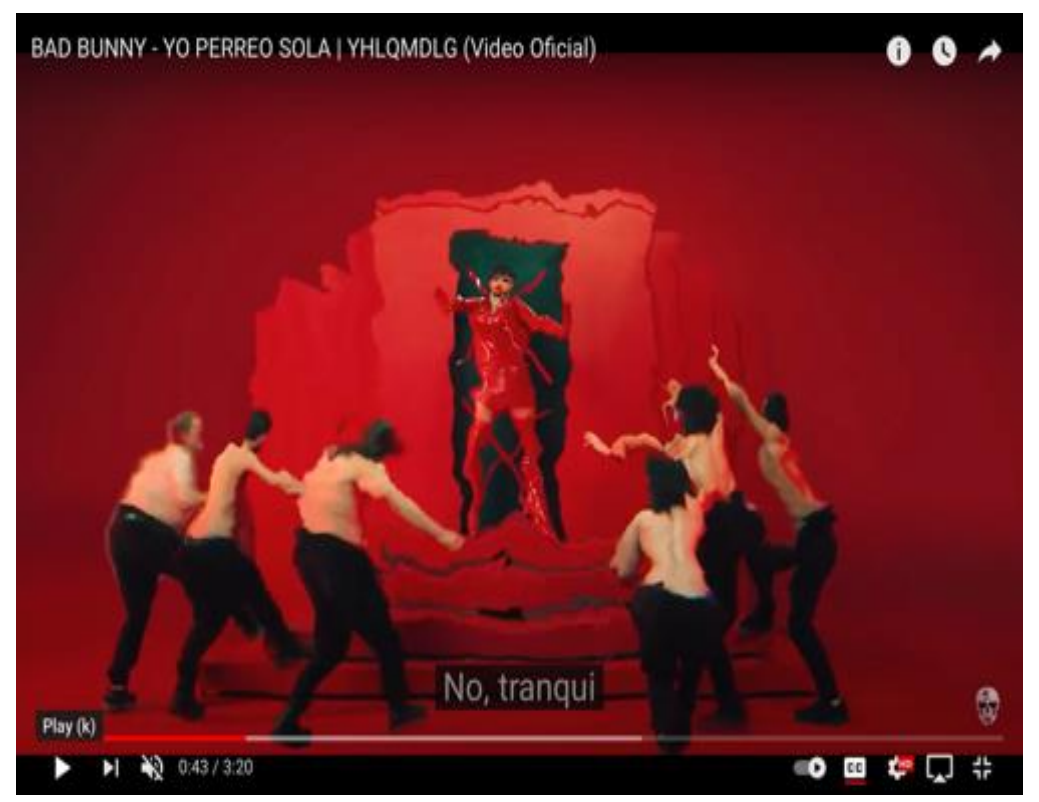

Figure 2.

In scene 2 (Figure 3 and 4), a dark green room is the setting where two bid signs are on the wall. Each of these signs have a message that alludes to making awareness to the sexual aggression and social injustices that women have faced in society. The signs contain the phrases: Ni una menos (Not one less) and La mujeres mandan (women rule). The first sign reminds the audience about the social movement which helps preventing the sexual harassment on women in their work area. On the other hand, the second sign also reminds the audience that women have the power to make their authority worth the decision about what they allow to be done to them. These two signs are in the room being the greatest focus in order to identify them and their meaning. Not only do they remind the audience or show the message behind the song, but they empower women.

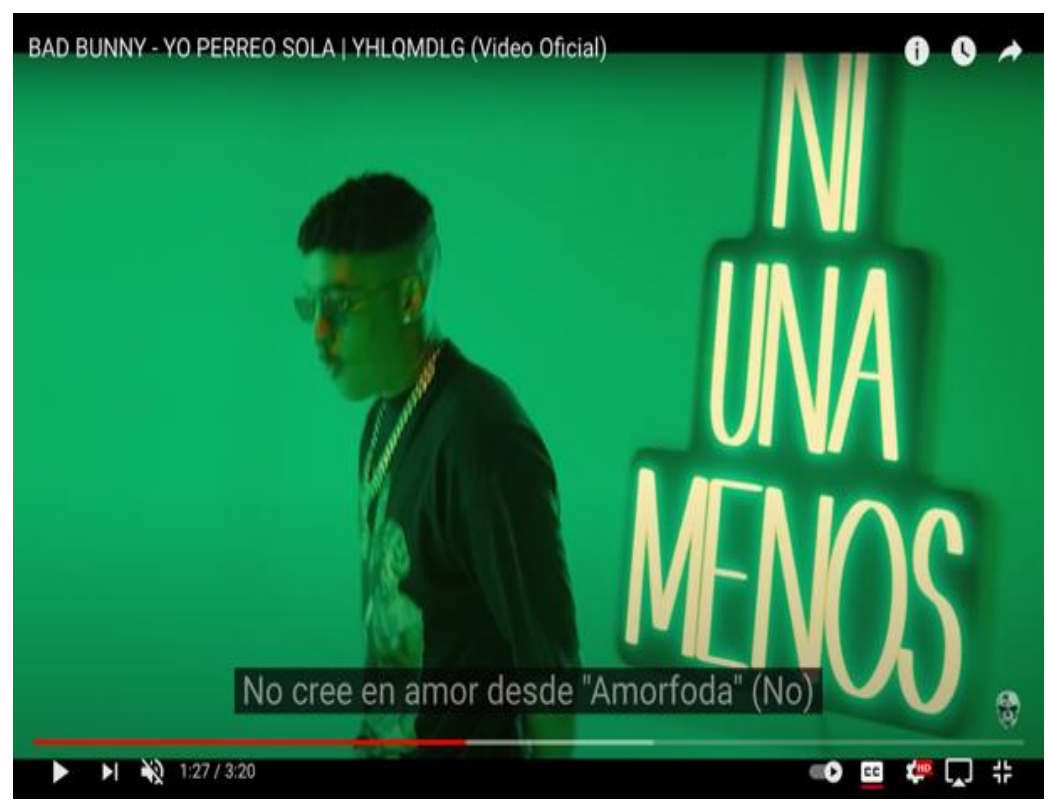

Figure 3. 


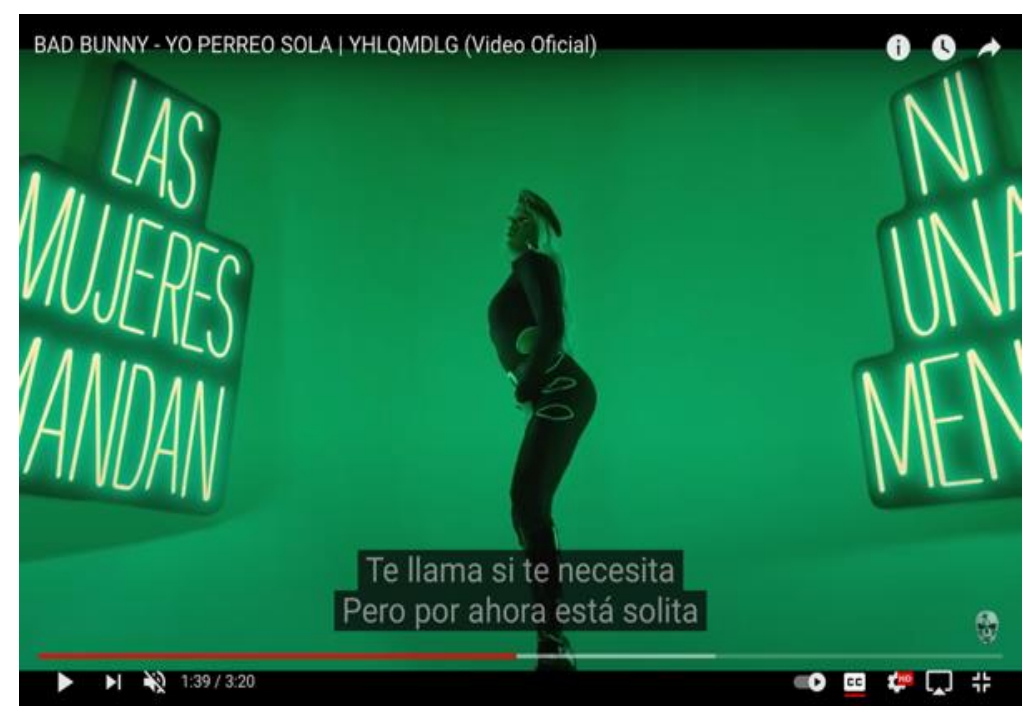

Figure 4 .

In scene 3 (Figure 5), the video presents the same singer tied with multiple chains and a dress code used by slaves back in the days. These images symbolize the resistance that men should adopt if a woman does not want to have any type of socialization with him. It also symbolizes breaking the barriers from toxic masculinity, prohibiting the man from his freedom since he is not having the right behavior in society. In other words, this presents what should happen to men since they are not able to control their desire for women. In addition, the other representation of this scene is how strong the harassment from men that the society would have to resort to treatment similar to one would use for dangerous species.

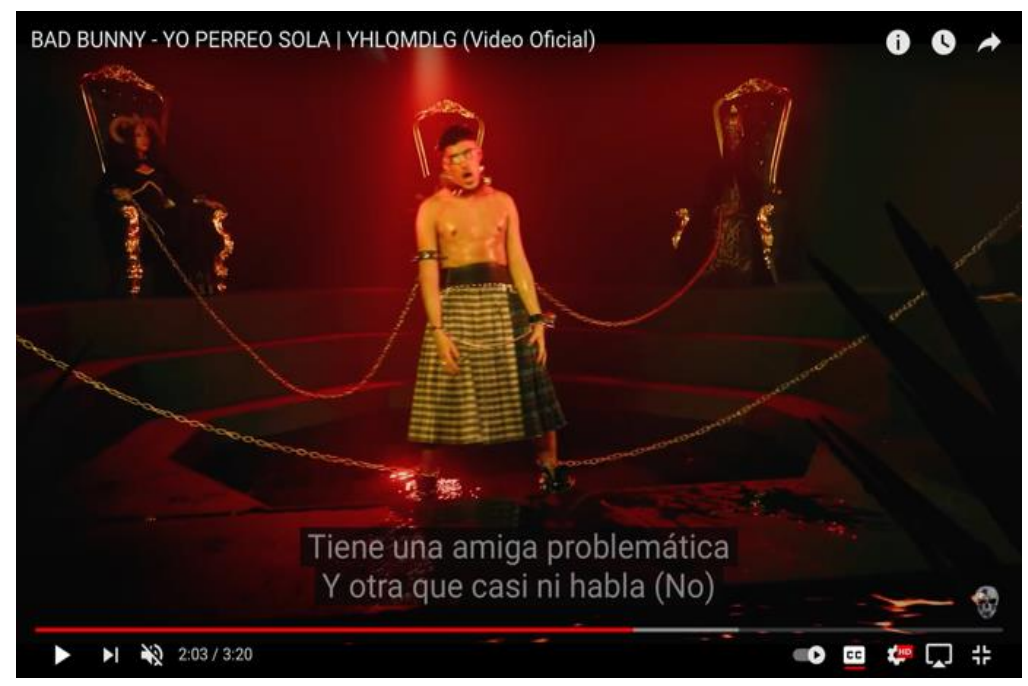

Figure 5 .

The three scenes interpret the reality lived by women and the reality that they would once like to live. In general, this video tries to inform what is happening with women and men in a confrontation. It is important to also mention the role which the singers play in the video who is dressed as a woman being a man in real life. This subjectivity supports feminist and brings empowerment to women by showing support with the action of dressing as one of them. In addition, men are taking for granted that women would always want to socialize with them or approve of them having physical contact with them. The song together with the video present the real view of women and what they would do if the scenario as the video was possible for them. 
Therefore, with the message of the visual in the video, the singer pretends to show men that they should respect and resist their force or sexual desire towards women.

\section{Discussion}

Society has had this gender role idea about men and women for a long period of time and it might look difficult to destroy this barrier or beliefs and behaviors. Thus, as presented above, there are various activists and movements which work to accomplish the expected result which would be for women to be treated equally and with respect over men. As it was stated above and agreeing with the authors (Blackstone, 2003; Connell, 2005; Flood, 2015), this goal requires great support especially from the male population of the world. Even when it might be a difficult task, the benefits that this can bring are great for society. Women and girls would not only feel free to perform their daily activities at any time of the day, but would also feel comfortable doing any type of activity. Looking at the serious and painful side of the situation, the world would face less murders and unfair situations, especially those that involve men and women through acts of violence. A lot of these situations are acts that leave families without a daughter, cousin, sister or even a mother. These are just a few, but enough reasons to contribute to stop this inequality among female members of the society.

\section{Conclusion}

In conclusion with this paper, women and men should always be aware that there are people who would help them to respect their rights. It is important that singers and other forces of actions get involved in reminding and making awareness that as society we have better behaviors to adopt. This would not only help to prevent the harassment of women, but also help to prevent many unfair deaths. This paper has presented the analysis of a reggaeton song alluding to the equality for women and their respect in situations where men become perpetrators of their innocence. The analysis also suggests the importance of society adopting and supporting better behavior to help movements and programs to achieve their desired goal.

\section{Acknowledgements}

This research did not receive any specific grant from funding agencies in the public commercial, or not-for-profit sectors.

The author declares no competing interests.

\section{References}

Basham, R. (1976). Machismo. Frontiers: A Journal of Women Studies, 126-143.

Blackstone, A. (2003). Gender roles and society. In J. Miller, R. Lerner \& B. Lawrence (Eds.), Human Ecology: An Encyclopedia of Children, Families, Communities, and Environments (pp. 335338). ABC-CLIO.

Butler, J. (1990). Gender trouble, feminist theory, and psychoanalytic discourse. In L. Niholson (Ed.), Feminism/postmodernism (pp. 324-341). Routledge.

Chant, S., and M. Guttman (2000). Mainstreaming men into gender and development. Working Paper. Oxford: Oxfam GB. 
Connell, R. W. (2003). Masculinities, change, and conflict in global society: Thinking about the future of men's studies. The Journal of Men's Studies, 11(3), 249-266.

Connell, R. W. (2005). Change among the gatekeepers: Men, masculinities, and gender equality in the global arena. Signs: Journal of Women in Culture and Society, 30(3), 1801-1825.

Fairclough, N. (2013). Critical discourse analysis: The critical study of language. Routledge.

Flood, M. (2015) 'Men and gender equality'. In M. Flood \& R. Howson (Eds), Engaging men in building gender equality (pp. 1-31). Cambridge Scholars Press.

Kaufman, M. (2003). The AIM framework: Addressing and involving men and boys to promote gender equality and end gender discrimination and violence. UNICEF, March, 31.

Machin, D., Mayr, A. (2012). How to do critical discourse analysis: A multimodal introduction. Sage Publications.

Paredes, A. (1971). The United States, Mexico, and "machismo". Journal of the Folklore Institute, 8(1), 1737.

Appendix: Analysis table

\begin{tabular}{|c|c|c|c|}
\hline Visual semiotic choices & Scene 1 & Scene 2 & Scene 3 \\
\hline $\begin{array}{l}\text { Attributes: ideas and } \\
\text { values communicated by } \\
\text { objects. }\end{array}$ & $\begin{array}{l}\text { Women must approve } \\
\text { for men to approach } \\
\text { them. }\end{array}$ & $\begin{array}{l}\text { Allude to the } \\
\text { movement Ni una } \\
\text { menos. }\end{array}$ & $\begin{array}{l}\text { Symbolizes the } \\
\text { resistance to harass } \\
\text { women and to break } \\
\text { the barrier to toxic } \\
\text { masculinity. }\end{array}$ \\
\hline $\begin{array}{l}\text { Settings: are used to } \\
\text { communicate ideas, to } \\
\text { connote discourse and their } \\
\text { values, identities and } \\
\text { actions. }\end{array}$ & $\begin{array}{l}\text { The pretended setting } \\
\text { is at a club. }\end{array}$ & Dark green room & $\begin{array}{l}\text { A ring where the } \\
\text { man is chained to } \\
\text { prevent his } \\
\text { harassment. }\end{array}$ \\
\hline $\begin{array}{ll}\text { Salience: } \\
\text { - } & \text { Potent cultural symbols } \\
\text { - } & \text { Size } \\
\text { - } & \text { Color } \\
\text { - } & \text { Tone } \\
\text { - } & \text { Focus } \\
\text { - } & \text { Foregrounding } \\
\text { - } & \text { Overlapping }\end{array}$ & $\begin{array}{l}\text { Potent cultural } \\
\text { symbols: } \\
\text { Size: the woman } \\
\text { appeared in a higher } \\
\text { altitude than men. } \\
\text { Color: Red } \\
\text { Tone: shiny dress } \\
\text { code } \\
\text { Focus: the magic } \\
\text { force the woman uses } \\
\text { to reject men. } \\
\text { Foregrounding: } \\
\text { Overlapping: }\end{array}$ & $\begin{array}{l}\text { Potent cultural } \\
\text { symbols: } \\
\text { Color: Green } \\
\text { Tone: bright lights in } \\
\text { the sings. } \\
\text { Focus: the message of } \\
\text { the sings. } \\
\text { Foregrounding: } \\
\text { Overlapping: }\end{array}$ & $\begin{array}{l}\text { Potent cultural } \\
\text { symbols: chains } \\
\text { Color: Black } \\
\text { Tone: slave dress } \\
\text { code } \\
\text { Focus: the man } \\
\text { forbidden from his } \\
\text { freedom } \\
\text { Foregrounding: } \\
\text { Overlapping: }\end{array}$ \\
\hline
\end{tabular}

